\title{
LEADERSHIP, SCHOOL IMPROVEMENT AND EFFECTIVENESS: THE EXPERIENCES OF THE SCHOOLS COMMUNITY IN ETHIOPIA
}

\author{
Dawit Legesse Edamo, Tshilidzi Netshitangani \\ University of South Africa, South Africa \\ E-mail: 53341562@mylife.unisa.ac.za, Netsht1@unisa.ac.za
}

\begin{abstract}
This was a qualitative research, which explored how the school community experienced the outcomes of leadership on the effectiveness of the school improvement program (SIP) on Sidama Zone schools, Ethiopia. Four schools were purposively selected. Data were collected using interviews, focus group discussions, observation and documents, which included school plans, reports, minutes of meetings, memos, letters and the students' examination results were analyzed as they reflected issues related to the outcomes of the SIP on the school's effectiveness. Principals, teachers, students, supervisors, parent teacher association members and SIP experts were interviewed. The findings indicate that in schools where there is strong collaboration of the school community in the planning, decision-making, monitoring and evaluation processes, the improvement initiatives are owned by all in the school and the performance of the schools is enhanced. It is recommended that the roles of the principals be redirected, the number of supervisors be increased, diverse professional development opportunities for principals and teachers be created, the recruitment, appointment and retention of principals be reconsidered and mechanisms to check school plans and performance reports be created.
\end{abstract}

Keywords: stakeholder collaboration, qualitative research, theory of change, school community, school support, student performance.

\section{Introduction}

Improving school leadership is considered one of the actions that can enhance the performance of schools. Ethiopia has launched leadership improvement initiatives as part of the overall school improvement program (SIP) to improve the quality of education offered to school children (M.o.E., 2011a). However, when new programmes like the SIP (in the Ethiopian context) are implemented, it is likely that challenges will be faced, even when the programmes result in certain benefits. Therefore, the outcome of any new programme should be investigated to sustain its positive effects and to identify areas of weakness for further improvement. Unfortunately, as noted by education researchers, in Ethiopia, there is a shortage of studies on quality of education (Derebssa, 2008, p. 3; Solomon, 2008, p. 5).

Research indicates that leadership capacity to manage change is critical for school improvement (Marsh, 2015, p. 72). Leadership is crucial to realising school improvement (Cravens \& Hallinger, 2012, p. 59, \& Abbott, 2015, p. 145). Harris and Muijs (2005, p. 14) point out that school improvement requires leadership to be the responsibility of all in the school. The school community (teaching and non-teaching staff, the students and their parents) need to participate in the improvement process. Together they have to make decisions that affect the school. If this takes place in the schools, it means that everybody is sharing the responsibility equally and all are accountable for whatever happens. Collaboration results in greater success than individual attempts do. 
Dawit Legesse EDAMO, Tshilidzi NETSHITANGANI. Leadership, school improvement and effectiveness: The experiences of the schools community in Ethiopia

\section{PROBLEMS \\ OF EDUCATION \\ IN THE $21^{\text {st }}$ CENTURY Vol. 76, No. 5, 2018 \\ 588}

Two conflicting ideas arose from the reflections of academics in Ethiopian universities: some argued that the leadership was indeed providing the necessary support to the school community, while others maintained that those who were expected to provide the necessary support were busy with out-of-school duties. These contrasting ideas are the basis on which this paper was conceptualised. The researchers decided not to depend on mere reports about the outcomes, successes and challenges of the leadership domain of the SIP, but rather to explore these in practice.

International research shows that more attention is given to theoretical traditions and development of models than to the practical aspects of leadership, school improvement and school effectiveness (Scheerens, 2013, p. 1-2). This research reveals the impact of the leadership domain on the effectiveness of schools.

\section{Leadership, School Improvement and School Effectiveness}

Research indicates that the leadership's capacity to manage change is critical for school improvement (Marsh, 2015, p. 72). Cravens and Hallinger (2012, p. 159) and Abbott (2015, p. 145) also emphasise that leadership is a key to realising school improvement. Research has in fact found a cause-effect relationship between leadership and school improvement. For this reason, the leadership in schools should have a clear vision of what the school will look like after carrying out efforts to improve the school. All who are concerned with the school's undertakings should also own this vision. Harris and Muijs (2005, p. 15) describe the role of leadership as initiating change by providing the necessary vision and support for bringing about improvement in the school. They also note that leadership and school improvement are closely interrelated. Schools, which improve and become effective are characterised by strong school-wide leadership and a shared vision. Against the background of such a shared vision, the leadership in schools should aim to give direction and assistance to the school community. This facilitates accomplishing the intended targets of the change.

Furthermore, school principals are supposed to take responsibility for increasing trust in the school community by working in collaboration with the communities and becoming pedagogical leaders (Arlestig \& Tornsen, 2014, p. 857). To realise the ambition of improved schools and student achievement, schools need to exercise a democratic form of leadership, which Pont, Nusche and Moorman (2008, p. 81) refer to as leadership that is "devolved", "dispersed", "shared", "teamed" and "democratic". Similarly, Harris and Muijs (2005, p. 14) emphasise the fact that school improvement requires leadership to be the responsibility of all in the school. It is also true that collaboration results in greater success than individual attempts. The leadership therefore needs to involve the whole school community in decisions that affect both the community and the functioning of the school. Moreover, teacher leadership can be realised as teachers engage in dialogue with their colleagues and share ideas to solve problems. In schools where the teachers play different leadership roles, the performance of the schools becomes better.

It has also been indicated that "...if teachers possess sufficient knowledge and skill... students' performance will improve" (Gokce, 2010, p. 498). The teachers become risk-takers and work for the achievement of the school's goals. Teachers are more able to implement new ideas within the context of supportive collaborative relationships or partnerships. Creating a collaborative environment encourages the teachers to work together to employ new ways of doing things and teach their subjects. This assists schools in becoming more effective. Decentralising decision-making and increasing collaboration in the education system means that decisions are then based on local contexts. This increases the commitment and partnership of the school community.

In line with this, an important issue to be considered is the time teachers, principals and supervisors allocate to important school matters. Principals and supervisors play instructional leadership roles. They have to devise different strategies and support the teachers in the 
school. Principals therefore ought to have sufficient time to provide the required support and to communicate with the parents and the community. Pont et al. $(2008$, p. 10) substantiate this observation when they underline the fact that principals, as instructional leaders need the time as well as the capacity to contribute to practices that affect teaching and learning positively. In addition, principals have to strive to create positive learning environments. While making schools autonomous, it is crucial to give them activities with a clearly defined scope and the school leadership has to play its role within that scope.

\section{Theory of Change Model}

The theory of change model underpins the research on which this article is based. School improvement as a change or reform process requires active participation of the school community. The existing school culture has to be changed, and the school community has to be convinced to take the initiative to improve their school. The school community includes the students, teachers, parents, administrators and the other staff at the school (Gold, Simon \& Brown, 2009, p. 244). In effecting change, the school community has to take responsibility, with the understanding that they are accountable for the outcomes. The theory of change model shows that by acting responsibly and accountably, the school community can run school improvement activities, which will enhance school effectiveness. This model has enabled the researchers to explain the variables "school community", "educational outcomes", "school improvement" and "school effectiveness".

The model indicates that there is a strong link between school community capacity and school improvement. Empowering the school community for effective participation in the implementation of school improvement requires changing the existing culture. Gold et al. (2009, p. 243) maintain that "one source of a school's resistance to reform is their culture and power structure". Unless the school culture is changed, it will be difficult to achieve the intended targets of the change process.

Studies indicate that awareness creation workshops and training sessions that aim to change the existing culture and awareness need to be presented to those who are involved in the change process. For example, Alaba (2010, p. 159) is of the opinion that for school improvements to be effective, "relevant workshops and training should be provided to teachers". It makes sense that the students' achievement will be maximised if those who implement the change receive appropriate training and participate in the process of change. Letsholo (2006, p. 6) emphasises that as part of building the school community, parents need to support their children. Unless parents/guardians work together with the school and follow up on their children's education, it will be difficult to maximise the students' achievement, which is assumed to be made possible through school improvement efforts.

The theory of change model also takes into consideration that there must be public accountability, while the school community members play the roles assigned to them. Nash $(2012$, p. 7) stresses that accountability makes the schools responsible for what the country needs in terms of social, economic and moral targets. This is the notion that should guide school communities when they play their roles. It calls for the full support of the community in creating a school environment, which is conducive to teaching and learning. The accomplishment of these interrelated tasks will contribute to the improvement of the school and its effectiveness. These views were used as a basis to explore the experiences of the school community with regard to the effect of the SIP on school improvement and effectiveness. 
Dawit Legesse EDAMO, Tshilidzi NETSHITANGANI. Leadership, school improvement and effectiveness: The experiences of the schools community in Ethiopia

\author{
PROBLEMS \\ OF EDUCATION \\ IN THE $22^{\text {st }}$ CENTURY \\ Vol. 76, No. 5, 2018 \\ 590 Methodology of Research
}

\title{
General Background
}

The research was conducted in Ethiopia. A qualitative case research design, which was guided by a constructivist philosophy, was used. The research was aimed at exploring the experiences of the school community with regard to the outcomes the leadership domain of the SIP had on school effectiveness. The qualitative approach enabled the researchers to obtain multiple views on the outcomes of the programme from the participants in the research. The constructivist/interpretivist philosophy was used to allow the participants in the research to construct meaning through the qualitative approach. The epistemological view guiding the research was that there are multiple realities that can be discovered (Koro-Ljunberg et al. 2009, p. 693; Morrison 2012, p. 15). In constructivist/interpretivist research, the researchers, together with the participants construct meaning. The case research technique was used to investigate issues related to the research. Bassey (2012, p. 162) states that case studies help the researchers to explore experiences related to practices. Furthermore, Burton and Bartlett (2009, p. 64) also indicate that case studies can be employed to explore the experiences and practices in educational settings.

The research was conducted in 2016 at two primary and two secondary schools in Sidama Zone. The participants who took part in the research were SIP experts in the Regional Education Bureau (REB), the Zonal Education Department (ZED) and the Woreda Education Office (WEO) who are in charge of directing and following up the SIP implementation, and purposefully selected members of the school community. The SIP as a General Education Quality Improvement Package (GEQIP) component is a wide program. However, the research aimed at exploring the experiences of the school community with regard to the outcomes of SIP on school effectiveness at Sidama Zone schools. A zone is sub-division of a region/regional state and consists of a number of woredas. A woreda is a sub-division of a zone and is considered as equivalent to a district.

\section{Sample}

Two primary and two secondary schools in the rural area were purposively selected for the research. The schools were selected based on data collected by the Zonal Education Department about the performance of the schools. Schools that performed well (Schools One and Three) were selected so that their good practices can be disseminated to other schools. Poorly performing schools (Schools Two and Four) were selected to come up with strategies that might help to rectify their weaknesses.

As indicated, a purposive sampling strategy was used to select information-rich cases. This allowed for the generation of comprehensive descriptions of the experiences of the school community with regard to the outcomes of the leadership domain. Data were collected from two SIP experts from Regional Education Bureau (REB), two SIP experts from ZED, two SIP experts from WEOs and from different members of the school community involved in the implementation of the SIP at school level. These included four principals of the four schools, four supervisors of the schools, four head teachers, 20 parent teacher association (PTA) members in the four schools (five members from each school), 28 teachers (seven from each school) and 28 students (seven from each school) of the four schools. Four school principals, 28 teachers, 28 students, 4 supervisors, 20 parent teacher association (PTA) members, 4 head teachers and 2 SIP experts were selected. 
Dawit Legesse EDAMO, Tshilidzi NETSHITANGANI. Leadership, school improvement and effectiveness: The experiences of the schools community in Ethiopia

\section{Instrument and Procedures}

A literature research, interviews, focus group discussions, observations and document analysis were used to obtain the essential data for the research. Individual interviews were conducted with principals and supervisors. One focus group discussion was conducted with teachers, PTA members and students in order to triangulate the data I obtained through interviews and to make the interview data rich by additional insights (Coleman, 2012, p. 255). Each focus group consisted of between 5 to 7 individuals and each group had one focus group discussion which lasted for about forty (40) minutes. Non participant observation was also used to examine school improvement processes in the schools. A one week non participant observation in each of the schools was done. The intention was to understand what has improved since the implementation of the SIP. To this effect, Moore (2005, p. 333) argues that the results of a program becomes evident through observation. An observation checklist was used. Apart from making observations as activities of the day progressed. Researchers also attended meetings that were scheduled during the week of observations. The researchers systematically recorded what was observed using a checklist and emergent issues related to the research issue were recorded.

\section{Data Analysis}

The analysis of data obtained from the observations, individual interviews, focus group discussions and documents was done thematically, which entailed identifying, coding and categorising the primary patterns in the data (Yin, 2011). In trying to make sense of the data, transcriptions of interviews, focus group discussions and field notes were read and reread and tentative categories and sub-categories emerged. The literature, observation and experience assisted the researchers in identifying the final categories. Extracts from the raw data were selected and either paraphrased or suitable quotations from the written responses were selected as rich data to illustrate the categories. Emergent issues were also included while focusing on the research questions.

\section{Ethical Considerations}

The researchers ensured the use of informed consent forms, discussion of the interview agenda and time frame and the use of a tape recorder to ensure accuracy of information. In addition, the participants were assured of anonymity and confidentiality. The University of South Africa ethically cleared the research.

\section{Results of Research}

\section{The Planning of School Activities}

Successful planning assists schools in improving their performance. This happens if there is leadership guidance for the school community on how to make the plans. Regarding the involvement of the school community in the planning process, the participants of School Three mentioned that

(p)lanning is the key to achieve our goals. We bring all stakeholders to take part in the planning process. We set priorities of the plan by involving representatives of all the stakeholders. (Principal)

In this school, planning is the concern of all in the school. Each department gathers data from its members. Then, the data will be analysed, and a plan will be produced on agreed priorities (Head teacher). 
Dawit Legesse EDAMO, Tshilidzi NETSHITANGANI. Leadership, school improvement and effectiveness: The experiences of the schools community in Ethiopia

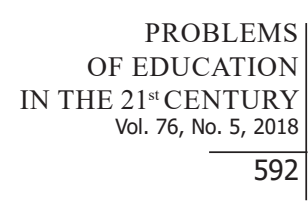

PROBLEMS

$21^{\text {st }}$ CENTURY

592

What seems apparent here is that there was participation on the part of the stakeholders in the planning of school activities. However, the idea of who is representing the students, the teachers and the parents in the planning process is important. A teacher in School Two commented as follows:

It is the principal who picks up representatives of teachers and parents. The nomination does not consider all necessary conditions such as commitment, experience and qualification. The principal uses his own criteria: the intimacy he has with the teachers.

This explanation shows that some problems were being experienced in the selection of the representative teachers to be engaged in the planning process. Yet, one of the students in School One indicated

(i)n my school, our representatives conduct meetings with students at each section level, and they gather information regarding our needs and problems. They collect our ideas to forward them during planning.

The students in School One seemed to be participating through their representatives. One of the students in School Four commented:

I do not know who is doing the planning for the school. The principal reads the plan of the school during general meeting at the beginning of the school year.

This comment indicates that the students in the school were not given the opportunity to be involved in the planning process. Moreover, in Schools Two and Four the teachers were of the opinion that they were not actively involved in setting priorities. One of the participants in School Two reflected as follows:

We always hear the principal saying, 'These are the priorities we have to focus for this year'. We cannot change what the principal proposes. Our participation is needed to endorse what is proposed by the principal.

This suggests that there could be some aggrieved feelings among the teachers regarding the planning process. In the same school, the researchers discovered that the annual plans were similar for two consecutive years, which could mean that there were no changes to the content of the plans.

\section{The Involvement of the School Community in Decision-Making and other Activities}

It emerged that the leadership in some schools seemed to be distributed, as there was participation of the school community in decision-making at different levels. This was communicated by the supervisor of School One:

There is no problem of participation in decision-making and other school activities. The school management always encourages the school community to participate in all sorts of activities...

The principals and supervisors in all the schools were of the opinion that decisions were made by involving all who had an interest in the school's activities. The students in School Three also confirmed that they were represented by their council members in decisions that particularly affected them:

Our representatives take part in all activities of the school. Members of students' council usually participate in decisions that affect students. They also participate in different meetings of the school. 
Dawit Legesse EDAMO, Tshilidzi NETSHITANGANI. Leadership, school improvement and effectiveness: The experiences of the schools community in Ethiopia

The description seems to point to the fact that the students of the school were empowered and played their roles in all kinds of activities in the school. However, to the contrary, it became evident that in School Two the participation of stakeholders was less than expected, as they did not participate properly in making important decisions. They said they were silenced and had to agree with what the principal decided. As the PTA members expressed it

(t)he principal feels that he is the only person to make decisions for the school. He makes decisions by himself and requests us only to endorse and sign on them.

It is not common to participate in day-to-day decisions in the schools. It is the responsibility of the school management to make decisions.

From the utterances of the participants, it seemed that they felt aggrieved. Even the head teacher did not participate in decisions that affected various practices in the school. This could mean that the rest of the school community did not own what the management decided.

\section{Principals Leading the Professional Development Activities of Teachers}

Three of the schools in the research area had staff development plans, which they intended to implement in the short and the long term. In these cases, the teachers were engaged in day-today self-improvement activities and prepared a portfolio of their own CPD experiences:

The school I supervise has a three-year staff development plan. It has made the staff engage in school-based learning activities. Each teacher plans for him/herself based on the broad school plan and produces a portfolio of his/her own CPD.... (Principal School Two).

My school works with cluster of schools in nearby distance. We have common meetings every month. We share best experiences with each other (Supervisor School Three).

Experience-sharing, as described above, may help schools to learn best practices and to improve their weaknesses. However, the supervisors indicated that although the schools were clustered to help them learn from each other, there were challenges affecting the effectiveness of experience-sharing. The supervisor of School Three confirmed this:

Teachers raise a number of questions for which we do not have answers. For example, they request for transport facilities, allowances and refreshments. But there is no budget to cover these expenses. These conditions are making leading CPD activities a challenge at cluster level.

This indicates that there was a shortage of the necessary facilities to run experiencesharing forums at cluster level. On the other hand, the participants in the four schools reflected that opportunities had been given to the teachers to attend upgrading courses. One of the experts in the education office had this to say: basis ...

We give opportunity (to teachers) of professional development to the staff on competitive

These seemingly convincing statements show that opportunities have been made available to the teachers to upgrade their qualifications from one level to the next. However, in some schools the teachers did not trust the principal as their leader. This is likely to affect the work environment and the performance of the school. An even more bitter complaint by one of the teachers in School Two was as follows:

I have served for 18 years, yet I could not get a single opportunity of training because I am not the type of person wanted by the ever changing principals... 
Dawit Legesse EDAMO, Tshilidzi NETSHITANGANI. Leadership, school improvement and effectiveness: The experiences of the schools community in Ethiopia

OF EDUCATION

IN THE $21^{\text {st }}$ CENTURY

Vol. 76, No. 5,2018

594

Rarely were opportunities for training seen to be given to Science and language teachers. Moreover, the workshops were not planned by the schools. In this regard, the teachers in School Two indicated that

(w)e see that some language and science teachers are sometimes invited to attend workshops organised by other organisations.

It was likely that the $\mathrm{CPD}$, which focused on the teachers' day-to-day activities, had become the concern of the education office, but refresher training and workshops were not arranged. Novice teachers were inducted with the help of mentors and a research module in the schools. Regarding this, the principal of School Four said that "New teachers ... engage in induction course".

However, the culture and practice of inducting new teachers was affected by some challenges, as mentioned by School Four participants:

The experienced teachers sometimes show resistance to serve as mentors ... They request for incentives (Supervisor School Four).

Spending time with new teachers is time consuming, and we do not get enough time for preparation of our lessons (Teacher School Four).

Both comments above indicate that there were problems with the implementation of the induction programme in the school.

\section{Leadership Support of the School Community}

The support that the leadership provides to the school community was another issue raised by the participants. As confirmed by the literature, leadership is one of the key factors affecting school effectiveness. In the research, it was found that strategies are used to support the staff, particularly the teachers, in all of the schools. Regarding leadership support, the principals maintained the following:

When some teachers face certain difficulties, I use coaching approach. I sit together with them, discuss on the problems and suggest ways to solve the problem (Principal School Three).

Sometimes, I discuss with individual teachers. But the two vice-principals are responsible to fully support teachers on daily basis (Principal School Two).

The two quotations above show that the principals provided limited support to the teachers. This was also observed by a teacher in School Two:

The principal does not have time to spend supporting teachers. He is mainly engaged in activities and meetings outside of the school. He comes to the school only two or three times...

In all the schools, it was evident that the principals were not at school when the schools were visited. It took the researchers a significant amount of time to arrange to meet them for interviews. Similarly, the supervisors provided the minimum support to the principals and the teachers:

...(M)y support, as I feel, is limited as I have to support the three schools in the cluster. They have diverse problems and it is difficult for me to address the concerns of all schools (Supervisor School Two).

The supervisor is not in a position to support us with the type of support we need. He is busy, visiting once in a while... (Teacher School One). 
Dawit Legesse EDAMO, Tshilidzi NETSHITANGANI. Leadership, school improvement and effectiveness: The experiences of the schools community in Ethiopia

The statements above show that supervisors were not providing adequate supervisory support, because they were expected to handle numerous issues in distant schools. Furthermore, the teachers' statements confirm that the supervisors were overloaded with work.

\section{Monitoring and Evaluating the School Improvement Activities}

School improvement activities have to be monitored in order to identify areas of weakness. In Schools One and Three, the participants reported that the school improvement committee members, nominated by the school community, were responsible for carrying out monitoring and evaluation. In the other schools, the principal, as indicated by the participants in the research appointed these committee members:

We have representatives from PTA who participate in monitoring and evaluation. We have nominated members who will participate in the school improvement committee... (PTA School Four).

... the school principal takes responsibility of carrying out day-to-day follow-up of the school's activities, and final evaluation (PTA School Four).

Apart from representatives being nominated to take part in the monitoring and evaluation process, the quotation above indicates that the students in the school participated in the leading, monitoring and evaluation of the improvement activities. This seems to imply that there is a structure in the school which facilitates the monitoring and evaluation of school activities. However, the participants felt that they were not actively involved in the monitoring and evaluation process. One of the PTA members in the school indicated this:

The school improvement committee is led by the principal and the principal is responsible to handle matters related to evaluation.

The PTA, in this sense, was not directly involved in the monitoring and evaluation of the activities in the school. The teachers in School Two complained that they were always asked to have group discussions and to report on what they felt, but what they reported was not contributing to improvement. As they said:

(t)hey tell us to discuss about what is going on in the school in one to five groups... but we do not see any change happening because of our discussions ... .

\section{Discussion}

\section{The Planning of School Activities}

Studies indicate that the capacity of schools' leadership to manage change affects the improvement initiatives of schools (Cravens \& Hallinger, 2012, p. 159). In schools where leadership is participatory, the school community is engaged in the planning process. This creates a better understanding of the business of schools among those concerned and facilitates the achievement of the planned goals. In addition, involving the right individuals as members of the planning team is considered to be a means of achieving success and plans based on needs assessment are considered to be a requirement to help schools meet their improvement targets (Center for Comprehensive School Reform and Improvement, 2006, p. 1; May, Huff \& Goldring, 2012; Stein, 2009). This was particularly true of Schools One and Three. These schools were considered to be model schools compared to the others. Thus, collaborative planning has helped Schools One and Three to become more successful. This is in line with the suggestions made by Makoelle (2011, p. 266). 
Dawit Legesse EDAMO, Tshilidzi NETSHITANGANI. Leadership, school improvement and effectiveness: The experiences of the schools community in Ethiopia

\section{PROBLEMS \\ OF EDUCATION \\ IN THE $21^{\text {st }}$ CENTURY Vol. 76, No. 5, 2018 \\ 596}

By contrast, in schools where the planning process was complicated by a number of problems, such as that the planning team members were not accepted by the school community, or only a few members or the principal with a few others produced a plan, or the principal alone took the responsibility to produce a plan for the school, what was planned did not bring about real improvement. Schools Two and Four were considered as less effective, probably, as the experience of the school community shows, because the planning processes used by the schools were not effective (Pont et al., 2008, p. 43). This appeared to hamper the achievement of the outcomes of the SIP as far as school effectiveness is concerned. It has also been noted that leadership in schools is a critical factor that determines the fate of schools, right from the planning stage (Bush, 2010, p. 650).

\section{The Involvement of the School Community in Decision-Making and other Activities}

The theory of change model indicates that participatory decision-making creates an enabling environment for the school community to engage in improvement processes (Gold et al., 2009, p. 244). The establishment of distributed decision-making in a school makes it possible for the school community to own the decisions (Weiner, 2014, p. 256). From the utterances of the participants, it seemed that they felt aggrieved. Even the head teacher did not participate in decisions that affected various practices in the school. This could mean that the rest of the school community did not own what the management decided.

In Schools One and Three the decision-making was participatory, and this resulted in the smooth functioning of the schools. This finding is similar to those reported by Hallinger and Huber (2012, p. 359). However, in schools where the decisions were made by the school management and only communicated to the school community, the school community felt that the management imposed the decisions, as they had not taken part in the decision-making process. This has negatively affected the level of the school communities' participation in the schools' activities and minimised the effectiveness of the schools. These findings are in line with those of Thoonen et al. (2012, p. 441). The section below deals with the leadership role played by principals in relation to continuing professional development (CPD).

\section{Principals Leading the Professional Development Activities of Teachers}

Comments by participants indicate that there were problems with the implementation of the induction programme in the school. However, an exploration of the ideas on how CPD is led indicates that the teachers in the schools were engaged in CPD activities through their involvement in day-to-day self-improvement tasks and experience-sharing with the cluster schools. Studies also confirm that networking and school-to-school collaboration can help the schools facilitate their professional development through experience-sharing among the teachers (Chapman \& Muijs, 2014, p. 351). Yet, as mentioned, the arrangements for experiencesharing at cluster level were hampered by a lack of the necessary facilities, such as the lack of transport for teachers to travel from their school to the cluster school, and the shortage of funds to cover the daily expenses of the teachers during cluster meetings. In addition to schoolbased CPD activities and experience sharing at cluster level, a number of teachers were also engaged in courses to upgrade their qualifications. Nevertheless, leading these CPD initiatives in the schools has been negatively affected by not only the shortage of facilities and the lack of support, but the resistance of teachers to engage in CPD activities or to induct newly deployed teachers, and by not recruiting and selecting teachers for upgrading courses, based on merit.

Moreover, the educational leaders at school level did not give attention to additional training, workshops, educational visits and distance course opportunities. However, these aspects were missing in the schools. The limited opportunities the teachers had to advance their profession were affected by the problems listed above. There were also no other strategies to influence the teachers to engage in learning. This may hinder schools in exploiting the full 
Dawit Legesse EDAMO, Tshilidzi NETSHITANGANI. Leadership, school improvement and effectiveness: The experiences of the schools community in Ethiopia

potential of their teachers and it may result in the poor performance of schools (Hoque \& Alam, 59 2011, p. 347).

\section{Leadership Support of the School Community}

Analysis of data shows that supervisors were not providing adequate supervisory support, because they were expected to handle numerous issues in distant schools. Furthermore, the teachers' statements confirm that the supervisors were overloaded with work.

For the smooth functioning of a school, the school community needs to be supported by the school leadership and the leadership needs to work according to certain ethical principles (Anderson et al., 2012, p. 427; Engel, 2011, p. 8; Firestone, 2014, p. 103; Shapiro \& Stefkovich, 2011, p. 27; Tang, Lu, \& Hallinger, 2014, p. 669). In addition, the leadership in the schools has to provide support and the essential resources to the school community to enhance the effectiveness of the school (Pine, 2009, p. 99). However, it was found in this research that the support given to the school community, particularly to the teachers, was limited for two reasons. Firstly, the principals were busy with out-of-school engagements, and they were unlikely to be found at the schools. This meant that the necessary support that should have been given to teachers, such as instructional leadership support, was absent. Pont et al. (2008, p. 43) observed similar findings. Most importantly, studies indicate that principals should be pedagogical leaders who work towards the common goal of improvement (Arlestig \& Tornsen, 2014, p. 857; Smith \& Engel, 2013, p. 107; Spangler, Tikhomirov, Sotak, \& Palrecha, 2014, p.080). But this research found that the leadership at school level is not strongly linked to school improvement initiatives. This is contrary to the findings made by Marsh (2015, p. 72). Yet, it has to be taken into account that the principals often work under great stress (Bellamy, Fulmer, Murphy \& Muth, 2007, p. 1).

Secondly, the supervisory support provided to schools was found to be limited. Only one supervisor is assigned to support a cluster of schools and it becomes difficult for the supervisors to cope with the diverse issues in the different schools. It also appears that School Four, being a new school, had more leadership-related problems than the other schools, as is likely to be the case in a new school.

\section{Monitoring and Evaluating the School Improvement Activities}

The teachers claimed that their discussions were not considered valuable enough to bring about changes to the ongoing practice in the school. This claim is a concern and it suggests that the teachers are not trusted enough to be agents of change.

In schools where the leadership was distributed, the school community took part in the monitoring and evaluation of school improvement activities and this is in line with the report of the Centre for Comprehensive Reform and Improvement (2006:3). In the four schools, the responsibility for monitoring and evaluating the school improvement plans and activities was given to the School Improvement Committee, of which the principal was the chairperson (M.o.E., 2011a, p. 3). The committee was entrusted with the responsibility to conduct monitoring and evaluation and had to report to the school community and the education offices. Yet, in Schools Two and Four the committee was evidently not trusted, as the members were selected subject to the personal biases of the principal, and the committee reported in the way the principal preferred. It has already been indicated that improvement teams with the wrong members cannot contribute to the effectiveness of schools (Centre for Comprehensive Reform and Improvement, 2006, p. 1). The lack of trust between the principals and the rest of the school community also reduced cooperation between them. The importance of building trust among school community members to ensure cooperation (Browning, 2014, p. 388) was not heeded in the schools. Although it has been outlined in the SIP documents that the supervisors monitor and evaluate the SIP processes (M.o.E., 2011b, p. 83), the data did not indicate the active participation of the supervisors in this process. 
Dawit Legesse EDAMO, Tshilidzi NETSHITANGANI. Leadership, school improvement and effectiveness: The experiences of the schools community in Ethiopia

\author{
PROBLEMS \\ OF EDUCATION \\ IN THE $21^{\text {st }}$ CENTURY \\ Vol. 76, No. 5, 2018 \\ 598 Conclusions
}

This research was intended to explore confusions about the outcomes of SIP, as there were various arguments regarding what the program had contributed to school effectiveness. The research could also help policymakers and educational officers to reconsider the SIP (including how it has been implemented). It may also provide policymakers and educational officers with strategies to improve SIP so as to enhance school effectiveness. International research also shows that, research done on school improvement, school effectiveness gives more attention to theoretical traditions, and the development of models than to practical aspects related to the school improvement processes. An investigation of the experiences of these stakeholders brings new insights to the fore and contributes to the improvement of practice. Thus, in terms of both methodology and findings, this research has successfully contributed to the field of knowledge in school improvement and school effectiveness by delving innovatively into the practical aspects of school improvement processes. The search also suggests possible solutions to the challenges occasioned by school leadership gaps in the implementation of effective school improvement programmes.

On the one hand, the findings reveal that in the schools where there was strong collaboration with the school community in the planning, decision-making, monitoring and evaluation processes, the improvement initiatives were owned by all in the school, and the performance of the schools was enhanced. On the other hand, a lack of collaboration with the school community on the above issues negatively affected the performance of other schools. In addition to this, in all the schools, the resistance of teachers, the lack of the necessary resources, poor recruitment procedures and a lack of selection procedures for upgrading the teachers' qualifications challenged CPD. The busy schedules of supervisors and the extensive engagement of principals in out-of-school duties and political roles have also resulted in weak leadership support to the school community. Thus, the findings indicate that a culture of support to the school community by the leadership is yet to be developed, and the researchers suggest that studies be conducted on a broader population.

The findings led to the recommendations for the improvement of the implementation of SIP. The first recommendation was that there is a need to redirect the roles of the principals and increase the number of supervisors. It sounds reasonable to redirect the roles of the principals and to have them focus on instructional leadership. This could be done by employing other officers in schools other than the principals' office which could be responsible to link the school with the external environment as the principals' main role is to be an effective leader in the school. Secondly, it is recommended that diverse professional development opportunities for principals and teachers be created. These trainings are crucial to equip the teachers with diverse curriculum delivery strategies. Further, the recruitment, appointment and retention of principals must be rethought. Rather than just being political appointees as per the findings, the schools need to have competent and qualified principals who can work towards the improvement of instruction in the schools. Lastly, it is also recommended that the education ministries should create effective mechanisms to check school plans and performance reports. Such recommendation is crucial because schools need to operate under a functional accountability system.

\title{
Note
}

This article is based on a doctoral research (Edamo, 2015) which was conducted to explore the way school communities experience the outcomes of the leadership on the effectiveness of SIP schools in Sidama Zone schools, Ethiopia. 
Dawit Legesse EDAMO, Tshilidzi NETSHITANGANI. Leadership, school improvement and effectiveness: The experiences of the schools community in Ethiopia

\section{References}

Abbott, I. (2015). Leadership and the reform of education. Journal of Education Policy, 30 (1), 145-146.

Alaba, S. O. (2010). Improving the standard and quality of primary education in Nigeria. International Journal for Cross-disciplinary Subjects in Education (IJCDESE), 1 (3), 156-160.

Anderson, S. E., Mascall, B., Stiegebauer, S., \& Park, J. (2012). No one way: Differentiating school district leadership and support for school improvement. Journal of Educational Change, 13, 403430

Arlestig, H., \& Tornsen, M. (2014). Classroom observations and supervision - essential dimensions of pedagogical leadership. International Journal of Educational Management, 28 (7), 856-868.

Bellamy, G. T., Fulmer, C. L., Murphy, M. J., \& Muth, R. (2007). Principal accomplishments: How school leaders succeed. New York: Teachers College Press.

Browning, P. (2014). Why trust the head? Key practices for transformational school leaders to build a purposeful relation of trust. International Journal of Leadership in Education: Theory and Practice, 17 (4), 388-409.

Bush, T. (2010). Leadership collaboration and learning outcomes. Educational Management Administration and Leadership, 38 (6), 650-653.

Centre for Comprehensive School Reform and Improvement (2006). When the plan becomes part of the problem. (Online). Retrieved from http://www.centerforcsri.org/files/TheCenter_NL_Mar06.pdf.

Chapman, C., \& Muijs, D. (2014). Does school-to-school collaboration promote school improvement? A research of the impact of school federations on student outcomes. School Effectiveness and School Improvement: An International Journal of Research, Policy and Practice, 25 (3), 351-393.

Chilisa, B., \& Preece, J. (2005). Research methods for adult educators in Africa. Hamburg UNESCO: Institute for Education.

Cravens, X. C., \& Hallinger, P. (2012). School leadership and change in East Asia: Building capacity for education reform. Peabody Journal of Education, 87 (2), 157-161.

Derebssa, D. (2008). Quality of teaching and learning in Ethiopian schools: Tension between traditional and innovative teaching-learning approaches. Available at http://www.hirochsima-u.2c,jp/cice

Edamo, D. L. (2015). Outcomes of the implementation of a school improvement programme in Sidama zone schools, Ethiopia. Unpublished doctoral thesis in Education Management. Pretoria: University of South Africa.

Engel, J. (2011). Ethiopia's progress in education: A rapid and equitable expansion of access. London: Overseas Development Institute.

Firestone, W. A. (2014). Teacher evaluation policy and conflicting theories of motivation. Educational Researcher, 43 (2), 100-107.

Gokce, F. (2010). Assessment of teacher motivation. School Leadership and Management, 30 (5), $487-$ 499.

Gold, E., Simon, E., \& Brown, C. (2009). A new conception of parent engagement: community organizing or

school reform. In F. English (Ed.), Sage handbook of educational leadership: Advances in theory, research and practice (pp. 237-268). Thousand Oaks, CA: Sage Publishing.

Hallinger, P., \& Huber, S. (2012) School leadership that makes a difference. International Perspectives, 23 (4), 359-367.

Harris, A., \& Muijs, D. (2005). Improving schools through teacher leadership. Berkshire: Open University Press.

Hoque, K. E., \& Alam, G. M. (2011). Impact of teachers' professional development on school improvement. Asian Pacific Education Review, 12, 337-348.

Letsholo, D. N. M. (2006). The implementation of parent-teacher conferences in the primary school. Unpublished master's dissertation. Pretoria: University of South Africa.

Makoelle, M. T. (2011). Exploring practices determining the effectiveness and improvement of secondary schools in the Free State Province. Unpublished doctoral thesis in Education Management. Pretoria: University of South Africa.

Marsh, S. (2015). A model for leadership that improves learning: New insights for schools and scholars. Leadership and Policy in Schools, 14 (1), 67-103.

May, H. Huff, J., \& Goldring, E. (2012). A longitudinal research of principals' activities and student performance. School Effectiveness and School Improvement: An International Journal of Research, Policy and Practice, 23 (4), 417-439. 
Dawit Legesse EDAMO, Tshilidzi NETSHITANGANI. Leadership, school improvement and effectiveness: The experiences of the schools community in Ethiopia

\section{PROBLEMS \\ OF EDUCATION \\ IN THE $21^{\text {st }}$ CENTURY \\ Vol. 76, No. 5, 2018 \\ 600}

Ministry of Education (M.o.E.) (2011a). Governing guidelines for the implementation of the school improvement program (revised). Addis Ababa: M.o.E.

Ministry of Education (M.o.E.) (2011b). School implementation programme implementation manual (revised). Addis Ababa: Andnet Printers.

Nash, T. (2012). School improvement. Education Journal, 140, 7-7.

Pine, G. J. (2009). Teacher action research: Building knowledge democracies. Thousand Oaks: Sage.

Pont, B., Nusche, D., \& Moorman, H. (2008). Improving school leadership. Volume 1: Policy and practice. Paris: Organization for Economic Cooperation and Development (OECD).

Scheerens, J. (2013). The use of theory in school effectiveness research revisited. School Effectiveness and School Improvement: An International Journal of Research, Policy and Practice, 24 (1), 1-38.

Shapiro, J. P., \& Stefkovich, J. A. (2011). Ethical leadership and decision-making in education. New York: Routledge.

Smith, K., \& Engel, K. S. (2013). Developing an assessment for learning (AfL) culture in school: The voice of the principals. International Journal of Leadership in Education: Theory and Practice, $16(1), 106-125$.

Solomon, A. (2008). Policy formulation, curriculum development and implementation in Ethiopia. Addis Ababa: Addis Ababa University Press.

Spangler, W. D., Tikhomirov, A., Sotak, K. L., \& Palrecha, R. (2014). Leadership motive profiles in eight types of organisations. The Leadership Quarterly, 25 (2014), 1080-1094.

Stein, L. B. (2009). The influence of parent and community involvement on local school councils in Massachusetts. Open Access Dissertations. Paper 28. (Online). Available at http://scholarworks. umass.edu/open_access_dissertations

Tang, S. L. J., \& Hallinger, P. (2014). Leading school change in China: A review of related literature and preliminary investigation. International Journal of Educational Management, 28 (6), 655-675.

Thoonen, E. E. J., Sleegers, J. C., Oort, F. J., \& Peetsma, T. T. D. (2012). Building school-wide capacity for improvement: The role of leadership, school organisational conditions, and teacher factors. School Effectiveness and School Improvement: An International Journal of Research, Policy and Practice, 23 (4), 441-460.

Weiner, J. M. (2014). Disabling conditions: Investigating instructional leadership teams in action. Journal of Educational Change, 15, 253-280.

Yin, R. K. (2011). Qualitative research from start to finish. New York, NY: Guilford Press.

Received: May 05, 2018

Accepted: September 05, 2018

Dawit Legesse Edamo

$\mathrm{PhD}$, Assistant Professor Hawassa University, Ethiopia. Department of Education Management, College of Education, Hawassa University, Ethiopia, P.O.Box 5,

Hawassa, Ethiopia

E-mail: 53341562@mylife.unisa.ac.za / ketajoredawit@gmail.com

Tshilidzi Netshitangani

Researcher, Associate Professor, Department of Educational Leadership and Management, College of Education, University of South Africa.

E-mail: Netsht1@unisa.ac.za 